\title{
Observations and modeling of post-midnight uplifts near the magnetic equator
}

\author{
M. J. Nicolls ${ }^{1}$, M. C. Kelley ${ }^{1}$, M. N. Vlasov $^{1}$, Y. Sahai ${ }^{2}$, J. L. Chau ${ }^{3}$, D. L. HyselI ${ }^{4}$, P. R. Fagundes ${ }^{2}$, F. Becker-Guedes ${ }^{2}$, \\ and W. L. C. Lima \\ ${ }^{1}$ School of Electrical and Computer Engineering, Cornell University, Ithaca, New York, USA \\ ${ }^{2}$ Laboratorio de Fisica e Astronomia, Universidade do Vale do Paraiba (UNIVAP), Sao Jose dos Campos, SP, Brazil \\ ${ }^{3}$ Radio Observatorio de Jicamarca, Instituto Geofisico del Peru, Lima, Peru \\ ${ }^{4}$ Department of Earth and Atmospheric Sciences, Cornell University, Ithaca, New York \\ ${ }^{5}$ Centro Universitario Luterano de Palmas (CEULP), Universidade Luterana do Brazil (ULBRA), Palmas, TO, Brazil
}

Received: 4 August 2005 - Revised: 1 February 2006 - Accepted: 21 April 2006 - Published: 3 July 2006

Part of Special Issue "The 11th International Symposium on Equatorial Aeronomy (ISEA-11), Taipei, May 2005"

\begin{abstract}
We report here on post-midnight uplifts near the magnetic equator. We present observational evidence from digital ionosondes in Brazil, a digisonde in Peru, and other measurements at the Jicamarca Radio Observatory that show that these uplifts occur fairly regularly in the post-midnight period, raising the ionosphere by tens of kilometers in the most mild events and by over a hundred kilometers in the most severe events. We show that in general the uplifts are not the result of a zonal electric field reversal, and demonstrate instead that the uplifts occur as the ionospheric response to a decreasing westward electric field in conjunction with sufficient recombination and plasma flux. The decreasing westward electric field may be caused by a change in the wind system related to the midnight pressure bulge, which is associated with the midnight temperature maximum. In order to agree with observations from Jicamarca and Palmas, Brazil, it is shown that there must exist sufficient horizontal plasma flux associated with the pressure bulge. In addition, we show that the uplifts may be correlated with a secondary maximum in the spread- $F$ occurrence rate in the post-midnight period. The uplifts are strongly seasonally dependent, presumably according to the seasonal dependence of the midnight pressure bulge, which leads to the necessary small westward field in the post-midnight period during certain seasons. We also discuss the enhancement of the uplifts associated with increased geomagnetic activity, which may be related to disturbance dynamo winds. Finally, we show that it is possible using simple numerical techniques to estimate the horizontal plasma flux and the vertical drift velocity from electron density measurements in the post-midnight period.
\end{abstract}

Correspondence to: $\mathrm{M} . \mathrm{J}$. Nicolls

(mjn25@cornell.edu)
Keywords. Ionosphere (Equatorial ionosphere; Modeling and forecasting; Ionospheric disturbances)

\section{Introduction}

It is well-known that the height of the $F$-region ionosphere is the major parameter in controlling the onset of equatorial spread $F$ (ESF) (Farley et al., 1970). This relationship is due to the fact that the growth rate for the generalized RayleighTaylor instability is inversely proportional to the ion-neutral collision frequency, which decreases exponentially with altitude (Kelley et al., 1979a). A second term in the growth rate depends on the eastward electric field, which is destabilizing after $F$-region sunset and stabilizing during the night as dictated by the nominal $F$-region electric field driven by the dynamo wind systems (e.g., Fejer et al., 1979).

Thus, it is no surprise that most observations of ESF are associated with the evening pre-reversal enhancement, during which the altitude of the ionosphere increases due to an increasing eastward electric field. The onset of ESF during this time period typically leads to a continuation of ESF throughout the post-sunset period, often beyond midnight, with an occurrence rate that decreases steadily throughout the night (Kil and Heelis, 1998; Hysell and Burcham, 2002). However, studies of post-midnight / pre-sunrise ESF have been fewer (e.g., MacDougall et al., 1998), since ESF during this time period is in general much weaker and occurs much less frequently. Most statistical studies of the occurrence rates of ESF (e.g., Abdu et al., 1983; MacDougall et al., 1998) use ionosondes, where the instabilities produce a measurable spreading in range or frequency on an ionogram trace.

Published by Copernicus GmbH on behalf of the European Geosciences Union. 


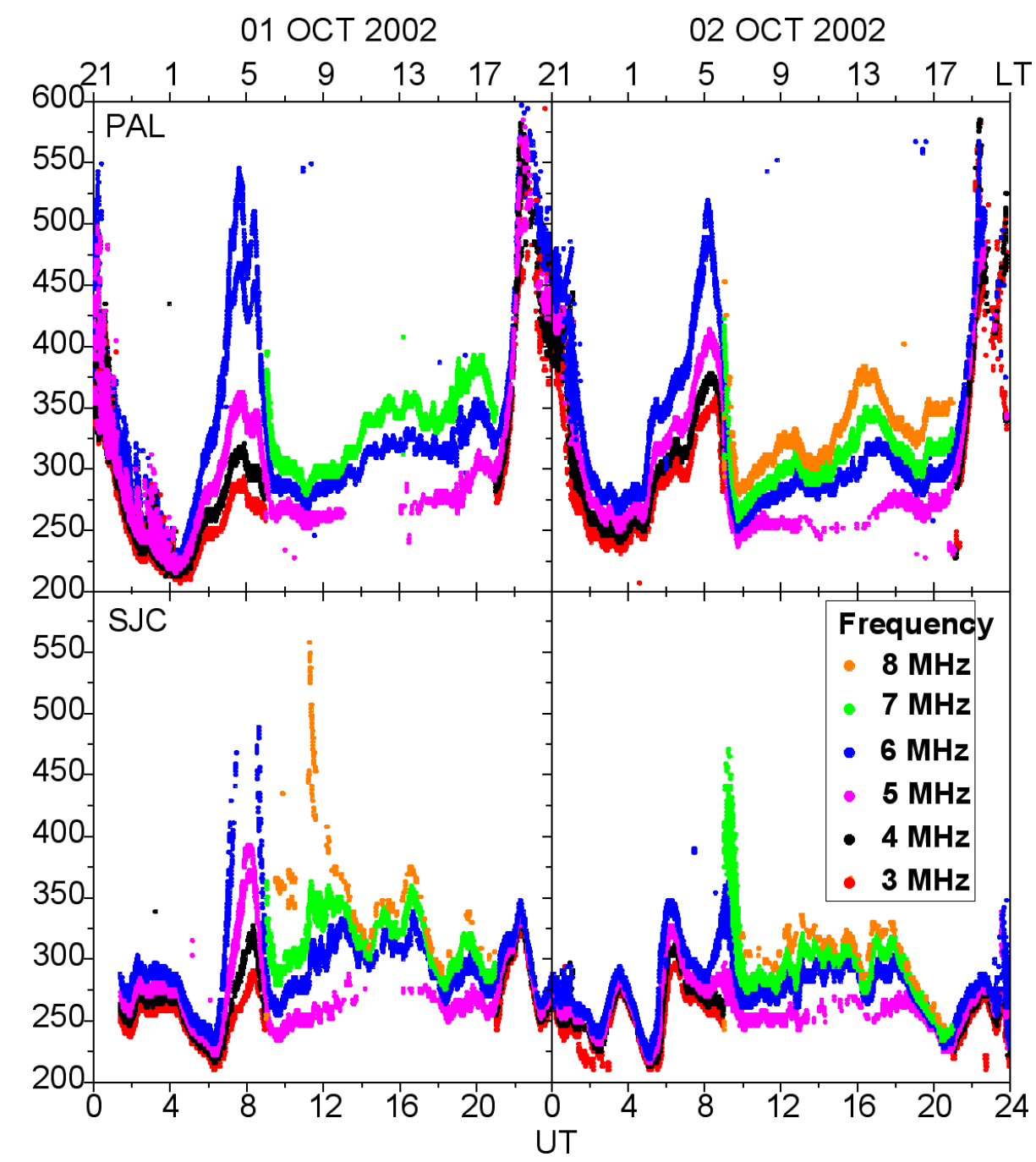

Fig. 1. Virtual height contours as measured in Sao Jose dos Campos and Palmas, Brazil, on 1 and 2 October 2002.

In this paper, we discuss what could be a source for a secondary post-midnight maximum in the ESF occurrence rate that has been reported by MacDougall et al. (1998), who observed eastwardly convecting irregularity patches coincident with "bottomside bulges". Such a maximum was also observed by Hysell and Burcham (2002). We show observational evidence from digital ionosondes in Brazil and a digisonde at Jicamarca, Peru for what we term "postmidnight uplifts", which may be the same phenomenon as the bottomside bulges. The term "uplift" refers to the observed increase in height of the $F$-region ionosphere. We note here that such a "lifting" does not say anything about the sign of the electric field because of other terms in the continuity equation.

We explain these uplifts in terms of phenomena associated with the midnight pressure bulge (e.g., Fesen, 1996). This pressure bulge is associated with a convergence of meridional thermospheric winds near the equator (e.g., Faivre et al., 2006), which produce interesting features such as the midnight temperature maximum (e.g., Sastri et al., 1994) and the midnight density maximum (e.g., Arduini et al., 1997).

We show that the uplifts are associated with a decrease in magnitude, but not a reversal, of the zonal electric field. A decrease in the magnitude of the westward electric field causes a waning of the reverse fountain effect (King, 1968). Using numerical simulations of the continuity equation, we show how the uplifts can occur despite the fact that the electric field does not change sign. We also focus on an extremely disturbed night during which the uplifts were amplified, and discuss how the uplifts may be enhanced by magnetic activity, which may be related to disturbance dynamo wind systems (e.g., Blanc and Richmond, 1980; Richmond et al., 2003). We also show some ESF statistics from Brazil that seem to support the idea that these uplifts could be the source of a secondary maximum in ESF occurrence rates. 


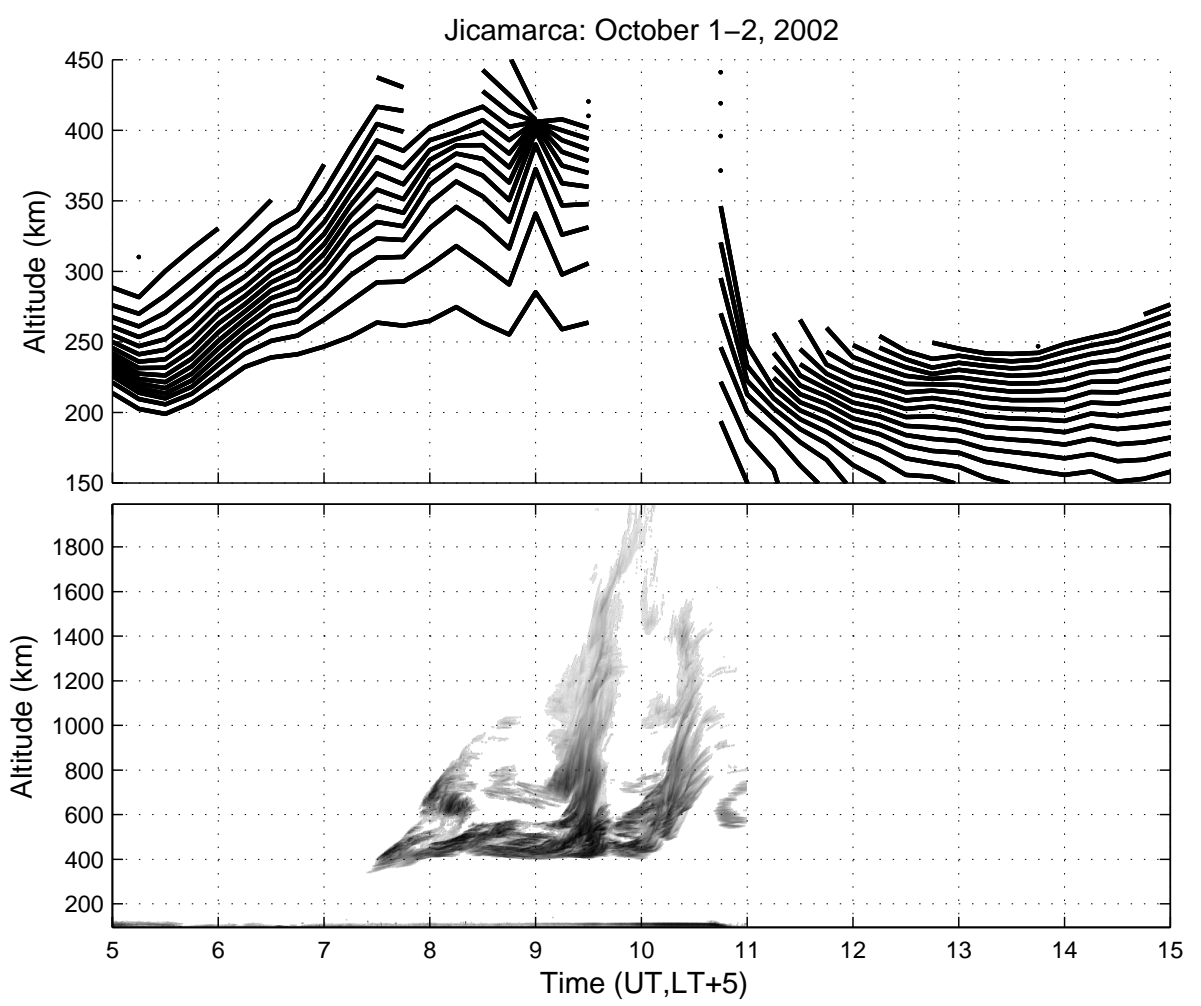

Fig. 2. Isodensity contours as measured by the Jicamarca digisonde on 2 October 2002 and measurements of coherent backscatter from the JULIA radar at Jicamarca.

\section{Observational evidence}

On the geomagnetically disturbed night of 1-2 October 2002, a series of large-scale traveling ionospheric disturbances (LSTIDs) propagated from high to low latitudes, causing large fluctuations in $N m \mathrm{~F} 2$ and $h m \mathrm{~F} 2$ as observed at the Arecibo Observatory $\left(18.34^{\circ} \mathrm{N}, 66.75^{\circ} \mathrm{W}\right.$, dip $\left.46^{\circ}\right)$. This event has been reported and discussed by Nicolls et al. (2004) and Vlasov et al. (2005). Nicolls and Kelley (2005) also showed that the final LSTID before sunrise caused the Arecibo ionosphere to rise to over $450 \mathrm{~km}$, and subsequently led to plasma structuring presumably due to some sort of instability mechanism.

In Fig. 1 we show observations from two digital ionosondes in Brazil on this interesting night along with the previous night (1 October). The panels are iso-density contours from Sao Jose dos Campos $\left(23.2^{\circ} \mathrm{S}, 45.9^{\circ} \mathrm{W}\right.$, dip $\left.-32^{\circ}\right)$ and Palmas $\left(10.2^{\circ} \mathrm{S}, 48.2^{\circ} \mathrm{W}\right.$, dip $\left.-11^{\circ}\right)$ in Brazil. On 2 October at the low-latitude station (Sao Jose dos Campos - SJC) we see oscillations in the height of the ionosphere induced by the propagating LSTID. These observations are very similar to those observed at Arecibo and are caused by the TID neutral winds coupled with a sufficient dip angle. At the equatorial station (Palmas-PAL) on this night we do not see these oscillations because of the much smaller dip angle. Instead, we see a large uplift of over $100 \mathrm{~km}$ between about
05:00 and 09:00 UT (02:00-06:00 LT). On the previous night (30 September-1 October), we do not see the oscillations associated with the LSTID. However, we do see an uplift at the equatorial station. It should be noted that on both 1 October and 2 October there was significant auroral electrojet (AE) activity, which could be a major cause of these height increases through disturbance electric fields. We discuss this possibility later.

In Fig. 2 we show observations from instruments at the Jicamarca Radio Observatory $\left(11.95^{\circ} \mathrm{S}, 76.87^{\circ} \mathrm{W}\right.$, dip $\left.1^{\circ}\right)$ on the night of 1-2 October. The upper panel shows isodensity contours measured by the Jicamarca digisonde, and the lower panel shows coherent backscatter as measured by the JULIA radar (Hysell and Burcham, 1998). A large uplift of over $100 \mathrm{~km}$ is observed in the ionosphere. During the uplift, strong post-midnight irregularities were observed with plumes reaching up to $2000 \mathrm{~km}$. It is interesting to note that the highest plume at about 04:30 LT coincides with the time that the irregularity structure was observed at Arecibo (Nicolls and Kelley, 2005). However, the apparent simultaneity of the events might be misleading because postmidnight ESF at Jicamarca normally occurs during this time period (Hysell and Burcham, 2002) and any disturbed electric fields, caused for example by the TID, could enhance pre-existing irregularities. 


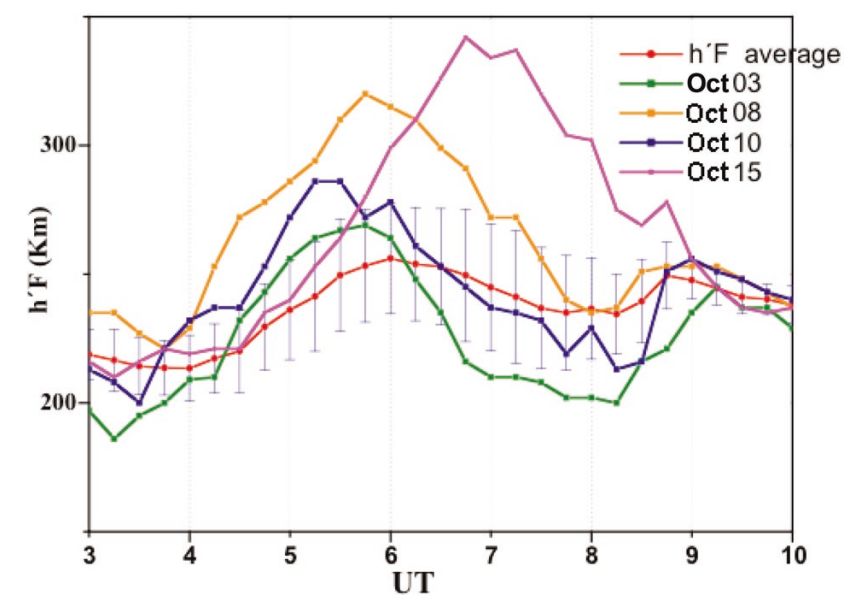

Fig. 3. Virtual height of the $F$ peak for several days in October 2002 along with the monthly average as measured at Palmas, Brazil.

The event on the night of 1-2 October 2002 was anomalous and coincident with a geomagnetic storm (Nicolls et al., 2004). However, the uplifts occur fairly regularly in the equatorial ionosphere with no strong correlation to Kp. This is illustrated by the fact that the uplifts occurred on the previous night of 30 September-1 October as well, which was a much quieter night (see Fig. 1). Figure 3 shows the virtual height of the $F$ peak for several other days in October along with the monthly average with errorbars corresponding to the standard deviation. We should note that while relatively quiet, these nights were all disturbed to some degree, as dictated by the auroral electrojet indices, especially several hours preceding the layer uplift. The quietest of the days, October 15, was preceded by weak AE activity on the previous day. We discuss the potential influence of auroral activity later, however we should emphasize that the uplifts appear to be a quiet-time phenomenon but strongly sensitive to auroral activity. The monthly average indicates an average uplift of about $50 \mathrm{~km}$ in the month of October 2002, with significant variations on that curve as noted by the example days.

The averages for many months between 2002 and 2004 are shown in Fig. 4. We have binned them here in terms of season into equinox and winter / summer, and we show foF 2 on the bottom and $h^{\prime} F$ data on the top (the virtual height of the $F$ peak). In the virtual height data, the uplifts are evident at equinox, and are especially pronounced during a couple of months (dark blue and orange curves) which correspond to October of 2003 and October of 2002, respectively. The uplifts are evident, however, in most of the equinox curves. In the winter/summer curves, the uplifts are not present except for a weak one in June of 2002 (red curve). The signature of the uplifts can also be seen in the $f o \mathrm{~F} 2$ data for equinox. After midnight, the density decreases relatively constantly at a rate of about $2 \mathrm{MHz}$ per hour as a signature of the reverse fountain effect. However, during the time of the uplifts, a slowing of the density decrease is observed to about $1 \mathrm{MHz}$ per hour, which should be expected. This is a result of a decrease in the recombination rate as the ionosphere rises. The seasonal variation of the uplifts and the role of the reverse fountain effect will be discussed later.

A similar plot as Fig. 4 using the Jicamarca digisonde is shown in Fig. 5. The data plotted here are from 2002, and each curve is a monthly average with the blue lines representing equinox months and the black lines representing winter/summer months. The uplifts are again evident in the post-midnight period (before 10:00 UT) in the equinox months. The magnitude of the average uplifts are not much different than those measured at Palmas, despite the nearzero dip angle at Jicamarca. The uplifts should not be confused with the significant rise in $h^{\prime} F$ after 10:00 UT. This spike in $h^{\prime} F$ may be caused by the low value of $f o \mathrm{~F} 2$ (near the lowest sounding frequency), which makes it nearly impossible to determine $h^{\prime} F$.

\section{Simulations of post-midnight uplifts}

In the preceding section, we showed evidence that postmidnight uplifts occur near the magnetic equator on a fairly regular basis. It is well-known that the zonal electric field is westward at night (e.g., Fejer et al., 1979; Kelley, 1989) and there is no reason to think that the zonal electric field is changing sign at this time since such a trend does not show up in long-term averages except perhaps during summer solstice, solar minimum periods. We show some case studies later that show that the reversal does not occur. There is a general trend, however, of smaller fields for all seasons during solar minimum conditions.

The major forces that can drive the ionosphere upwards besides the effect of electric fields are those caused by neutral winds and the horizontal advection of plasma, while recombination can cause an apparent motion leading to an uplift as we have defined it (see the introduction). We show in this section that the daily uplifts discussed in Sect. 2 can be explained by including the role of recombination in the continuity equation. Off the equator, winds and diffusion become important and enhance the uplifts. At the equator, there is really no way that winds can directly produce an uplift. For reference, a meridional neutral wind of several hundred meters per second would be required to produce a local uplift of $50 \mathrm{~km}$ over the course of an hour at the dip latitude of Jicamarca. Such magnitudes are not observed (e.g., Biondi et al., 1999). However, winds can indirectly produce an uplift through meridional advection of plasma, driven by a latitudinal gradient in electron density.

\subsection{Recombination}

The ionospheric response to recombination only is wellknown (e.g., Banks and Kockarts, 1973; Rishbeth and Garriott, 1969). However, we present a discussion here in order 


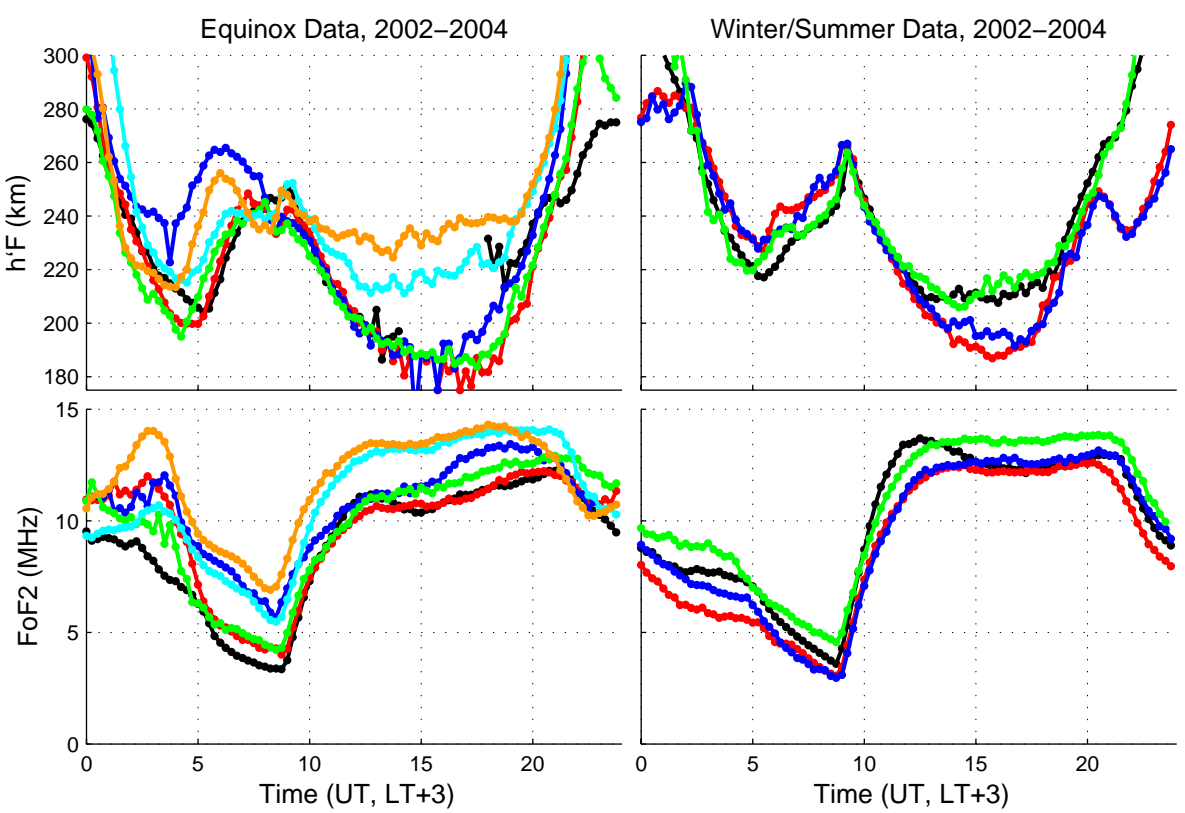

Fig. 4. Monthly averages of $f o \mathrm{~F} 2$ (left) and $h^{\prime} F$ binned into equinox and winter summer months as measured in Palmas, Brazil.

to illustrate the differences when a finite vertical drift is included.

For the Northern Hemisphere case, we define the $\hat{y}$ coordinate as parallel to the magnetic field, the $\hat{z}$ coordinate as perpendicular and north to the magnetic field (vertical at the equator), and the $\hat{x}$ coordinate as perpendicular and east to the magnetic field, and the vector velocity may be written as

$\mathbf{v}=\mathbf{v}_{\perp}+\mathbf{v}_{\|}=v_{\perp n} \hat{z}+v_{\perp e} \hat{x}+v_{\|} \hat{y}$.

The continuity equation is,

$\frac{\partial n_{e}}{\partial t}+\nabla \cdot\left(n_{e} \mathbf{v}\right)=P-L$

where $P$ and $L$ refer to production and loss terms, respectively. The continuity equation may be written as

$\frac{\partial n_{e}}{\partial t}+n_{e}\left(\nabla \cdot \mathbf{v}_{\perp}\right)+\mathbf{v}_{\perp} \cdot\left(\nabla n_{e}\right)+n_{e} \frac{\partial v_{\|}}{\partial x}+v_{\|} \frac{\partial n_{e}}{\partial x}=P-L$

There is no production term at night and the loss term is due to recombination, which is controlled by the reactions that convert $\mathrm{O}^{+}$to molecular ions (which then recombine dissociatively). The major reactions in the $F$-region are thus

$\mathrm{O}^{+}+\mathrm{O}_{2} \rightarrow \mathrm{O}_{2}^{+}+\mathrm{O}$

with reaction rate (St.-Maurice and Torr, 1978)

$$
\begin{aligned}
\gamma_{1}= & 2.82 \times 10^{-11}-7.74 \times 10^{-12}\left(T_{\text {eff }} / 300\right)+ \\
& 1.073 \times 10^{-12}\left(T_{\text {eff }} / 300\right)^{2}-5.17 \times 10^{-14}\left(T_{\text {eff }} / 300\right)^{3} \\
& +9.65 \times 10^{-16}\left(T_{\text {eff }} / 300\right)^{4} \mathrm{~cm}^{3} \mathrm{~s}^{-1}
\end{aligned}
$$

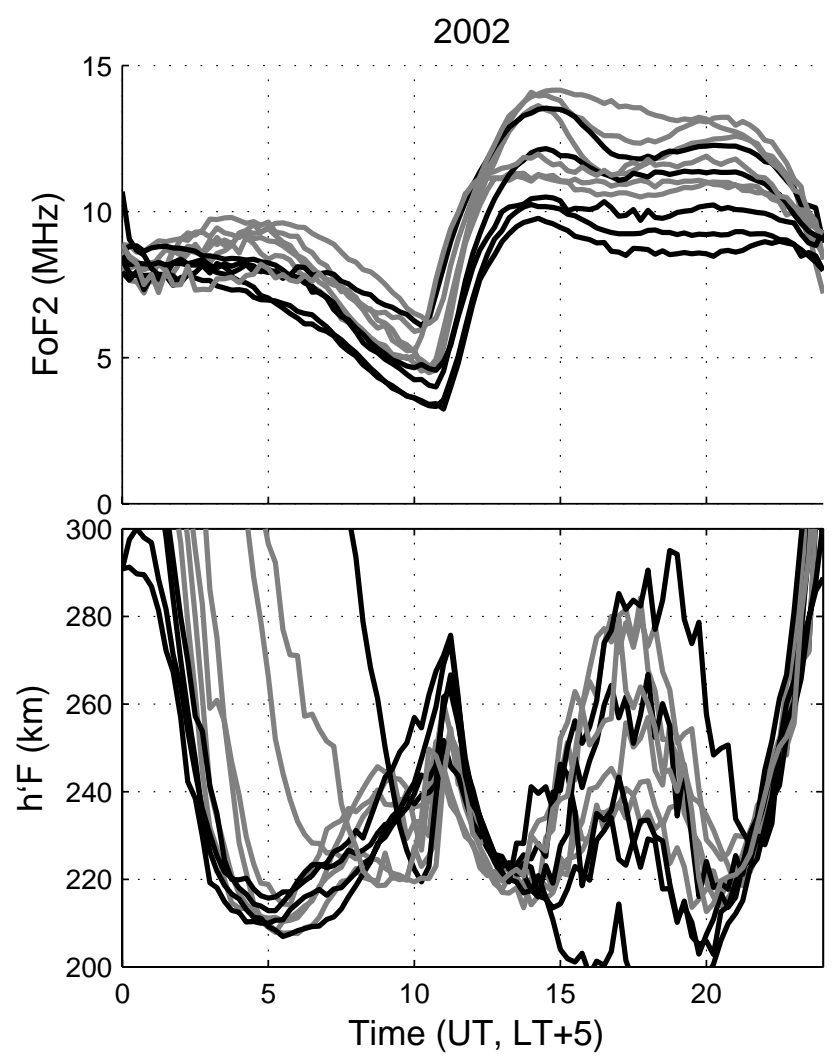

Fig. 5. Monthly averages of $f o \mathrm{~F} 2$ (top) and $h^{\prime} F$ (bottom) as measured by the Jicamarca digisonde. The black curves correspond to winter / summer data and the gray curves correspond to equinox data.

and 


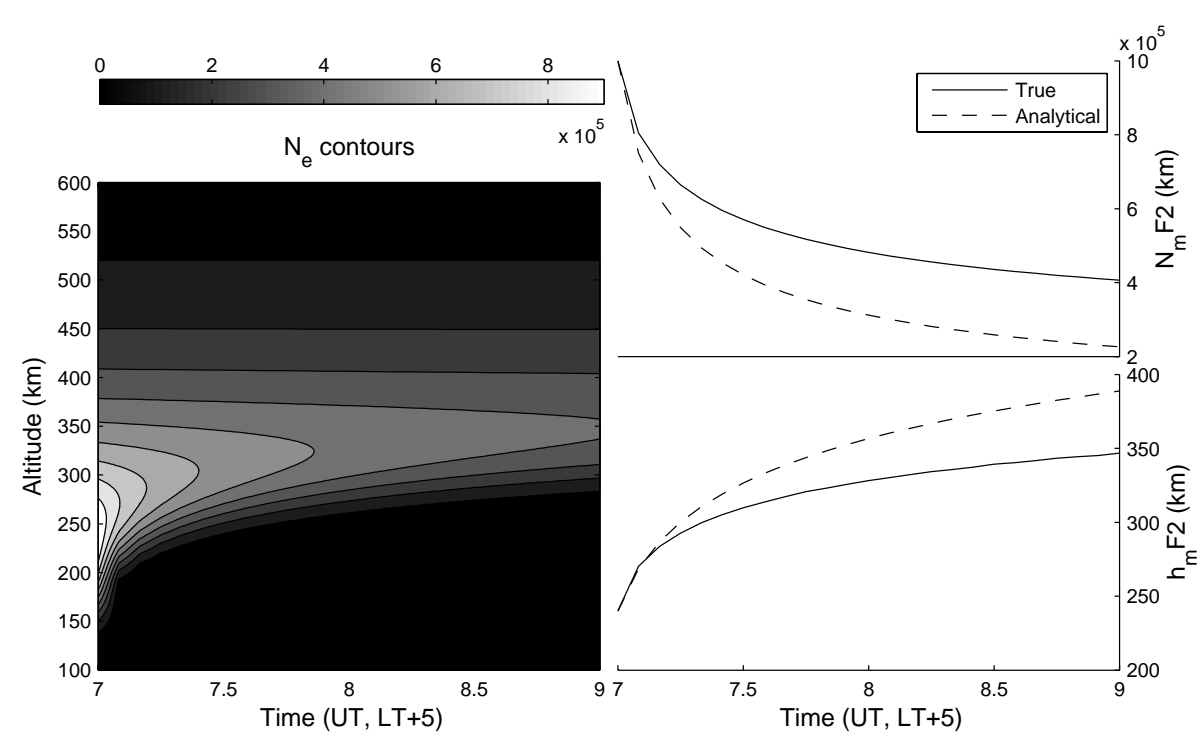

Fig. 6. Electron density as a function of time and altitude for the case of recombination only. The left panel is a contour plot of $n_{e}$. The right panel is $N m \mathrm{~F} 2$ (top) and $h m \mathrm{~F} 2$ (bottom). The solid lines correspond to the values using the recombination rate calculated from MSIS and the dashed lines correspond to the analytical solution of Eqs. (10) and (11).

$\mathrm{O}^{+}+\mathrm{N}_{2} \rightarrow \mathrm{NO}^{+}+\mathrm{N}$

with reaction rate (St.-Maurice and Torr, 1978)

$$
\begin{gathered}
\gamma_{2}=1.53 \times 10^{-12}-5.92 \times 10^{-13}\left(T_{\text {eff }} / 300\right)+ \\
\quad 8.6 \times 10^{-14}\left(T_{\text {eff }} / 300\right)^{2} \mathrm{~cm}^{3} \mathrm{~s}^{-1}
\end{gathered}
$$

where $T_{\text {eff }}=0.667 T_{i}+0.333 T_{n}$. The loss term can be written as $L=\beta n_{e}$ where $\beta$ is the recombination coefficient, $\beta=\gamma_{1}\left[\mathrm{O}_{2}\right]+\gamma_{2}\left[\mathrm{~N}_{2}\right]$. Then,

$\frac{\partial n_{e}}{\partial t}+n_{e}\left(\nabla \cdot \mathbf{v}_{\perp}\right)+\mathbf{v}_{\perp} \cdot\left(\nabla n_{e}\right)+n_{e} \frac{\partial v_{\|}}{\partial x}+v_{\|} \frac{\partial n_{e}}{\partial x}=-\beta n_{e} .(6)$

For the case at the magnetic equator, we first make the assumptions that there are no parallel or perpendicular-east gradients in electron density. Then, we are left with the vertical velocity (perpendicular-north) term. Assuming no vertical velocity, we obtain the simplest continuity equation dominated by recombination,

$$
\frac{\partial n_{e}}{\partial t}=-\beta n_{e}
$$

with solution $n_{e}(z, t)=n_{e 0}(z) e^{-\beta(z) t}$ where $n_{e 0}(z)$ is the initial density profile. The effect of recombination in the absence of a vertical drift is to eat away at the bottomside density, increasing the bottomside gradient, decreasing the peak density, and increasing the peak height.

If we let the initial density profile be a Chapman profile,

$n_{e 0}(z)=n_{m 0} \exp \left[\frac{1}{2}\left(1-\frac{z-z_{m 0}}{H_{c h}}-e^{\left(z_{m 0}-z\right) / H_{c h}}\right)\right]$, then there is an interesting analytical solution for the peak height and density in the case that $\beta$ is constant in time and decays exponentially in altitude with the Chapman scale height, i.e.

$\beta(z)=\beta_{0} e^{\left(z_{m 0}-z\right) / H_{c h}}$

where $\beta_{0}$ is the recombination coefficient at the peak. In this case, the altitude of the peak and the peak density can be shown to be

$z_{m}(t)=z_{m 0}+H_{c h} \ln \left[1+2 \beta_{0} t\right]$

$n_{m}(t)=\frac{n_{m 0}}{\sqrt{1+2 \beta_{0} t}}$

where $n_{m 0}$ and $z_{m 0}$ correspond to the peak density and altitude of the initial profile.

To demonstrate the behavior of the ionosphere under recombination only, we show an example in Fig. 6. In this case, we have taken the initial electron density profile to be a Chapman layer with scale height $H_{c h}=50 \mathrm{~km}$. The calculation is run for two hours and the neutral densities from the MSIS-90 model (Hedin, 1991) are used to calculate the recombination coefficient for the conditions in the early morning of 8 October 2002. The left-hand plot shows contours of electron density and the line plots show $N m \mathrm{~F} 2$ and $h m \mathrm{~F} 2$, along with $n_{m}$ and $h_{m}$ computed from Eqs. (10) and (11). It should be clear from these line plots that in general the recombination rate scale height is much lower than the Chapman scale height. As can be seen from the figure, the ionosphere rapidly recombines for a short period. The height of the ionosphere increases and the peak density decreases. There is an observed uplift. 


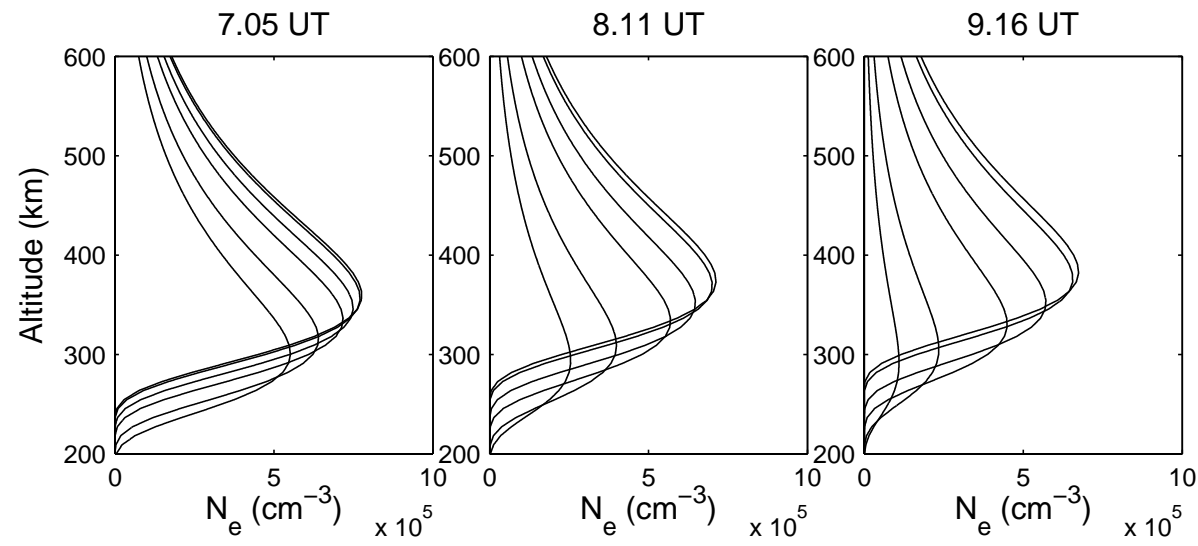

Fig. 7. Profiles of electron density about 1,2 , and $3 \mathrm{~h}$ into the simulation for constant downward velocities. The profiles with the lowest densities correspond to the highest downward velocities.

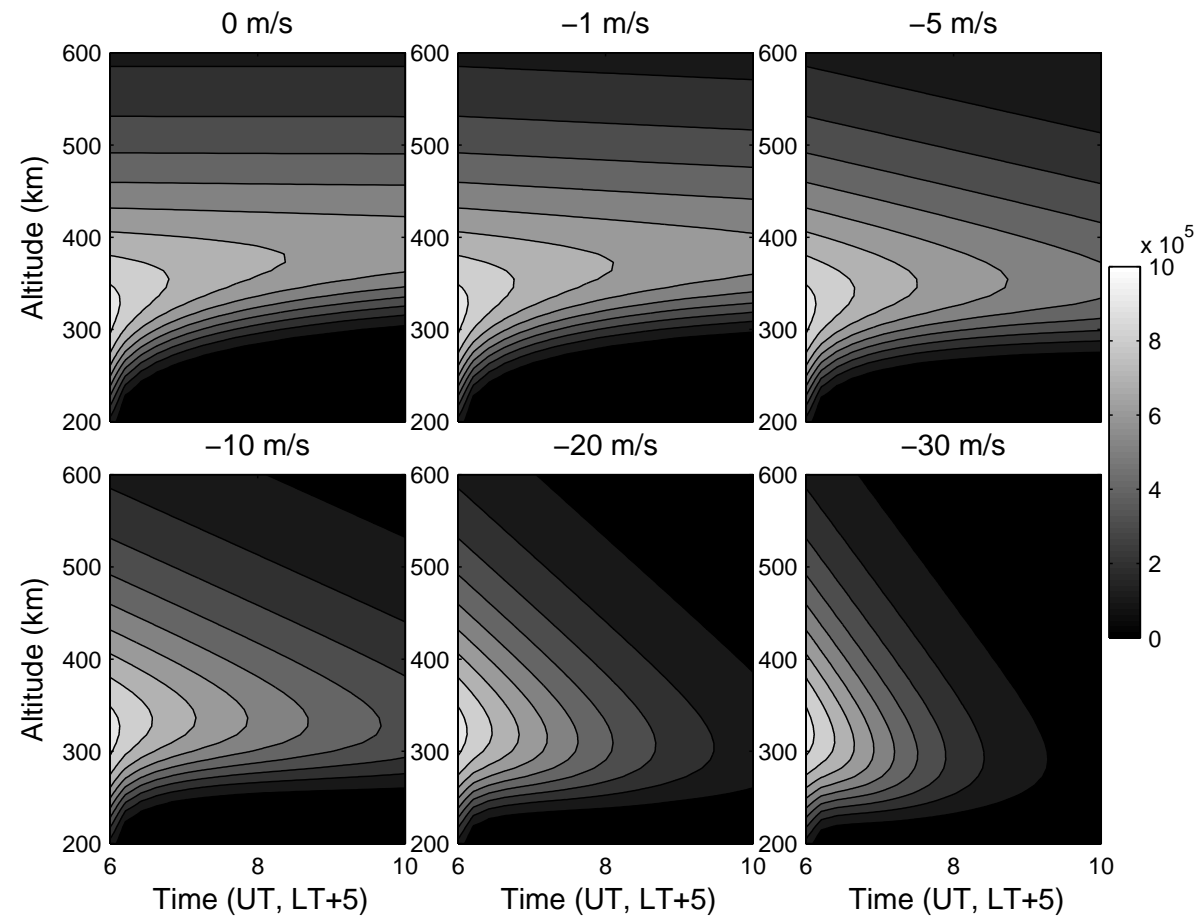

Fig. 8. Contour plots of the electron density for the different values of a constant downward velocity.

\subsection{The role of a finite vertical drift}

Now, let us consider the role that vertical motion plays in this process. Again at the magnetic equator, neglecting horizontal gradients, the continuity equation, Eq. (6), becomes

$$
\begin{aligned}
& \frac{\partial n_{e}(z, t)}{\partial t}+v_{z}(z, t) \frac{\partial n_{e}(z, t)}{\partial z}+n_{e}(z, t) \frac{\partial v_{z}(z, t)}{\partial z}= \\
& \quad-\beta(z, t) n_{e}(z, t)
\end{aligned}
$$

where we have strictly included the time and altitude dependences. $v_{z}$ in Eq. (12) refers to the $\boldsymbol{E} \times \boldsymbol{B}$ drift caused by a zonal electric field. Experimental data show that $v_{z}$ is ap- proximately uniform with altitude in the $F$ region in the postmidnight period so that the $z$ dependence can be dropped. Physical analytical solutions to this equation are difficult to obtain, even for a constant drift, and we must turn to a numerical approach.

To illustrate the effect of a finite vertical drift, we have run numerical simulations for the case of a constant westward electric field (downward drift) with varying magnitudes, which are plotted in Figs. 7 and 8. The initial profile was taken to be Chapman with a scale height of about $65 \mathrm{~km}$ and a peak density at $320 \mathrm{~km}$ of about $9.4 \times 10^{5} \mathrm{~cm}^{-3}$ 


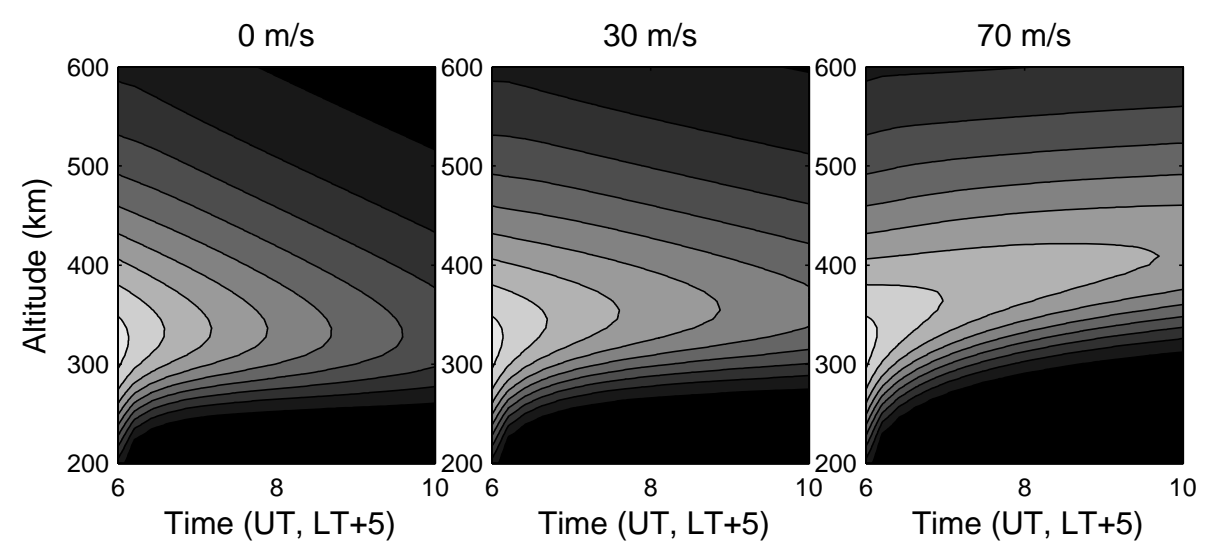

Fig. 9. Contour plots of the electron density for the different values of a constant neutral wind as described in the text. The scale is the same as that in Fig. 8.

corresponding approximately to the profile measured by $\mathrm{Ji}$ camarca at 01:00 LT (06:00 UT) on 16 April 2002. The simulations are run for $4 \mathrm{~h}$. Figure 7 shows profiles at about 1 , 2 , and $3 \mathrm{~h}$ into the simulation, for 6 different values of $v_{z}$ of $0,-1,-5,-10,-20$, and $-30 \mathrm{~m} / \mathrm{s}$. Figure 8 shows contour plots for each of the cases. The major observation from these curves is that a downward drift leads to a faster decline in density (as one would expect) and at some critical velocity can overcome the uplift induced by recombination.

However, real drifts are a function of time and possibly height. In Sect. 4.1, we will include the effect of a timedependent velocity.

\subsection{Diffusion and winds}

Off the equator, in addition to the electric field, ambipolar diffusion, gravity, and neutral winds become important and their role in the vertical velocity must be included in the continuity equation. Equation (12) becomes (e.g., Banks and Kockarts, 1973)

$$
\begin{aligned}
\frac{\partial n_{e}}{\partial t} & +\frac{\partial}{\partial z}\left[-D_{a} \sin ^{2} I\left(\frac{\partial n_{e}}{\partial z}+\frac{n_{e}}{H_{p}}\right)+v_{z} n_{e} \cos I\right. \\
& \left.-u_{n} n_{e} \sin I \cos I\right]=-\beta n_{e}
\end{aligned}
$$

where $D_{a}=k_{b} T_{p} / m_{i} v_{i n}$ is the ambipolar diffusion coefficient, $I$ is the magnetic dip angle, $H_{p}=k_{b} T_{p} / m_{i} g$ is the plasma scale height, $T_{p}=T_{i}+T_{e}, u_{n}$ is the northward neutral wind, $v_{i n}$ is the ion-neutral collision frequency, and we have ignored temperature gradients and other neutral motions. It can be expected that diffusion should reduce the magnitude of the uplifts but that neutral winds might enhance them in the case of an equatorward wind. Equatorward winds are observed at mid and low latitudes after midnight (e.g., Biondi et al., 1999), although there is an abatement of the wind (e.g., Herrero et al., 1993) associated with the midnight pressure bulge (e.g., Fesen, 1996), which is related to the convergence of winds near the equator (e.g, Faivre et al., 2006). Some analytical solutions to various simplified versions of this continuity equation have been obtained (e.g, Banks and Kockarts, 1973; Duncan, 1956; Dungey, 1956; Martyn, 1956; Rishbeth and Garriott, 1969; Vlasov et al., 2005). However, in general a numerical approach is necessary.

Examples of the behavior with winds, diffusion, and a vertical velocity are shown in Fig. 9 for a constant downward drift of $10 \mathrm{~m} / \mathrm{s}$ and three different values of equatorward wind: $0 \mathrm{~m} / \mathrm{s}, 30 \mathrm{~m} / \mathrm{s}$, and $70 \mathrm{~m} / \mathrm{s}$. The same initial profile as before was used and the simulation corresponds to the location of Palmas. At $0 \mathrm{~m} / \mathrm{s}$, we see a curve similar to that of Fig. 8 except with slightly increased falling velocity due to the inclusion of diffusion. At $30 \mathrm{~m} / \mathrm{s}$, we see a sizable uplift, and at $70 \mathrm{~m} / \mathrm{s}$, we see a huge uplift of almost $100 \mathrm{~km}$.

\section{Discussion}

\subsection{Comparison to observations}

In the previous section, we showed evidence that recombination induces an apparent uplift at the magnetic equator provided that the downward vertical drift (westward electric field) is sufficiently small. In this subsection, we compare our modeling results to some Jicamarca measurements.

On 16 April 2002, a mild uplift of 40-50 km was observed in the post-midnight period at Jicamarca. The radar was operating in the drifts (perpendicular) mode and densities were estimated using the differential phase approach (Feng et al., 2004; Kudeki et al., 1999). The measured velocity is shown in the top panel of Fig. 10 as the solid line, and a polynomial fit used in our simulation is the dashed line. The drift was assumed constant as a function of altitude. An initial density profile corresponding to a fit to the measurements was used, which corresponded to a bottomside scale near $65 \mathrm{~km}$ and a larger topside scale. $h m \mathrm{~F} 2$ as measured by Jicamarca is shown as the blue line in the second panel, and the model 


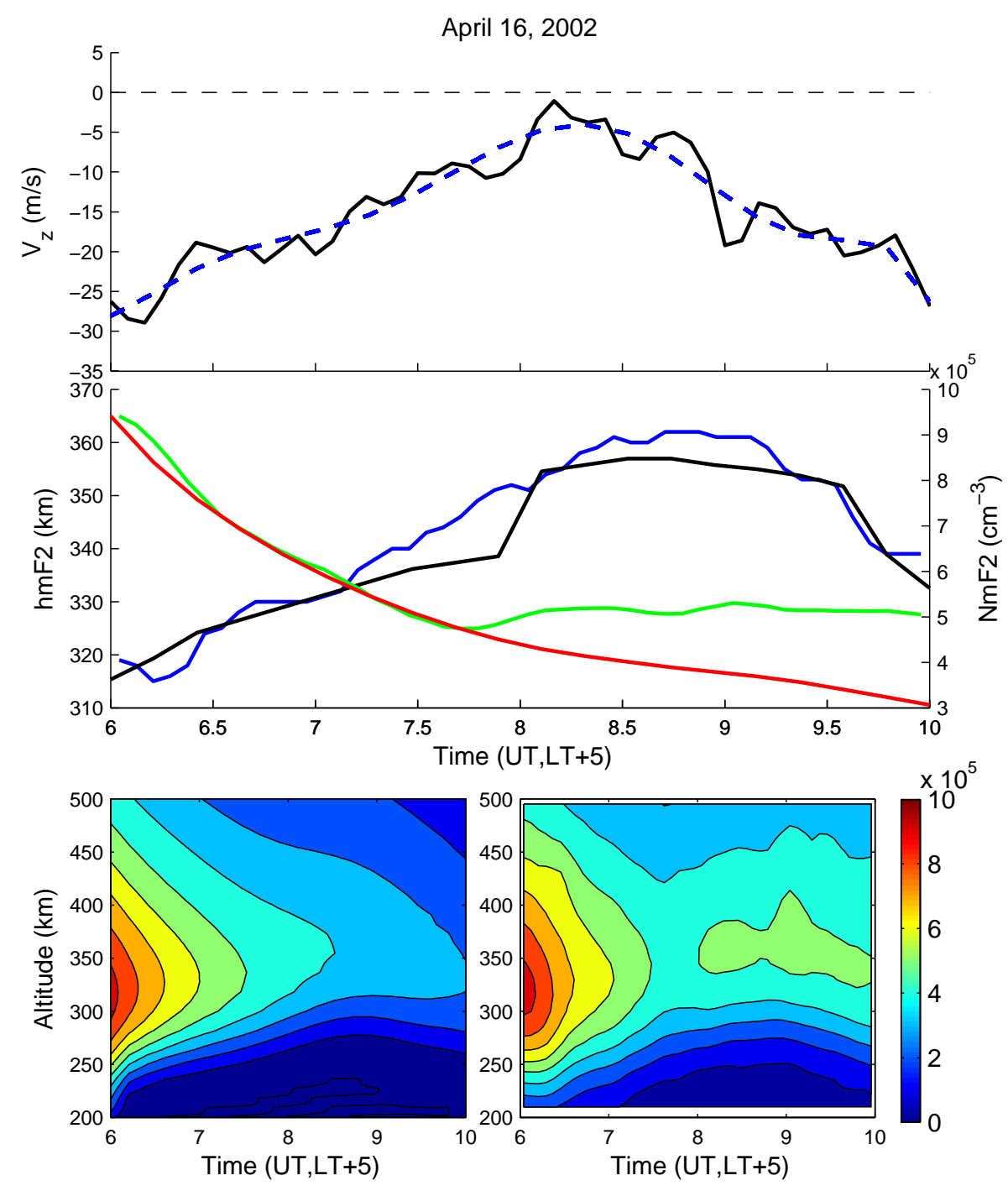

Fig. 10. Data and simulations on 16 April 2002. The top panel is the vertical drift measured by Jicamarca (black solid) and the drift used in the model run (blue dashed). The second panel is $h m \mathrm{~F} 2$ (measured in blue, modeled in black) and $N m \mathrm{~F} 2$ (measured in green, modeled in red). The lower panel is a density contour plot of the model (left) and measurements (right).

results are shown in black. $N m \mathrm{~F} 2$ as measured by Jicamarca is shown as the green line and the model results are shown in red. The lower panels show the modeled and measured densities as a function of height and time. We should note that we have increased the recombination coefficient slightly over the value given using the MSIS parameters for this case to match the observed density decrease.

The vertical drift is observed to decrease in intensity after about 01:00 LT to reach a minimum velocity of near $0 \mathrm{~m} / \mathrm{s}$ at 03:00 LT, at which point it increases again. This is a characteristic that is observed frequently during the uplifts. From the model behavior described in the preceding section, we would expect an uplift at this point and this is exactly what we see. The $h m \mathrm{~F} 2$ comparisons show that the model reproduces the uplift in height quite well. However, in comparing the densities, we see that up until about 03:00 LT, they agree very well, but after that point, there is a large discrepancy. In fact, $N m \mathrm{~F} 2$ increases, which can be seen more clearly in the color plot in Fig. 10 where we see a secondary maximum in density in the Jicamarca data. This maximum cannot be explained by including only recombination and the onedimensional plasma motion.

In order to explain this increase, we must consider additional sources of ionization. Possibilities include actual production (which seems unlikely at night), a shear in the vertical drift (the drift would have to increase in magnitude with increasing altitude), or a gradient in horizontal plasma flux, corresponding to either a meridional or a zonal gradient in electron density. A meridional plasma flux could be interpreted as the horizontal advection of the equatorial 


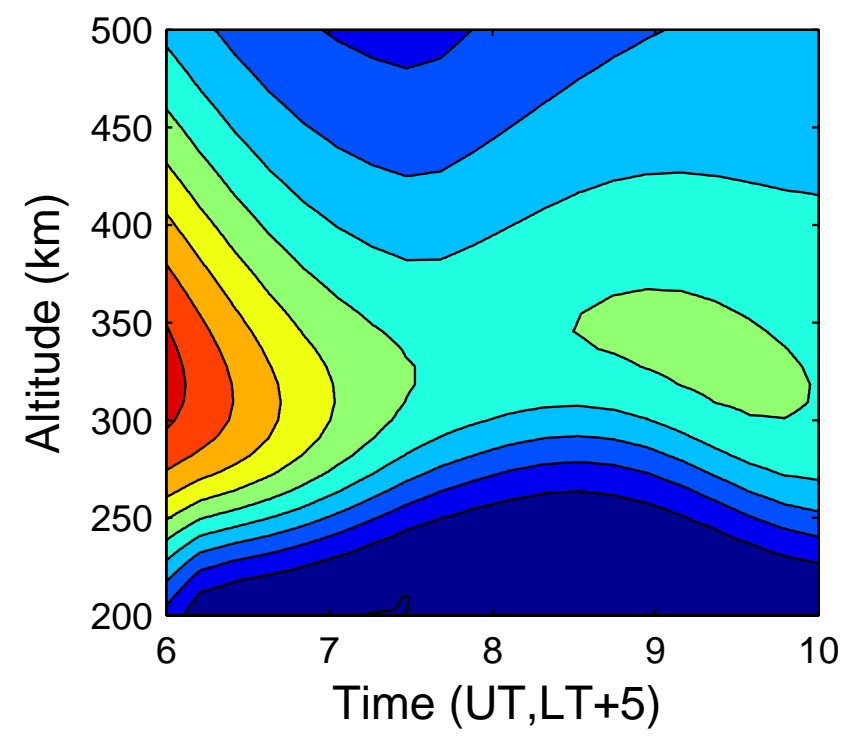

Fig. 11. Contour plot of modeled densities including a horizontal plasma flux term as described in the text. The scale is the same as in Fig. 10.

anomaly into the equatorial region, which seems to be the most likely explanation. This advection may be associated with the midnight pressure bulge caused by a convergence of thermospheric winds at low latitudes.

If we subtract the electron density data from the model to obtain the difference, and take the time derivative, we obtain an estimate of the ionization rate necessary for the model to agree with the data (this estimate is only approximate since it ignores recombination and is only calculated at the peak). We find that in this case the rate is close to constant after 02:30 LT with a value near $20-25 \mathrm{~cm}^{-3} \mathrm{~s}^{-1}$. Such an ionization rate seems too high to be caused by a shear in the vertical drift, implying that plasma flux must be the major source of ionization. Thus, the ionization rate gives us an estimate of the derivative (horizontal gradient) of the plasma flux. The total electron content transported to the equatorial region for such a horizontal plasma flux can be computed as $25 \mathrm{~cm}^{-3} \mathrm{~s}^{-1}$ multiplied by the vertical scale (about $100 \mathrm{~km}$ ) multiplied by the time scale of the flux. This flux persists for at least $2.5 \mathrm{~h}$, giving a total electron content of about 2.25 TECU $\left(1\right.$ TECU $\left.=10^{12} \mathrm{~cm}^{-2}\right)$ for a gradient in flux of $25 \mathrm{~cm}^{-3} \mathrm{~s}^{-1}$. This is a reasonable change in the vertically integrated electron density observed at at Jicamarca in the post-midnight period, which is typically greater than 10 TECU (e.g., Valladares et al., 2001). We note that our estimate of the flux and associated TEC increase is probably an upper limit.

Figure 11 shows the results of incorporating the necessary horizontal gradient in plasma flux, and we now see very good agreement with the observed density behavior with the model $N m \mathrm{~F} 2$ variation matching the data almost exactly. The

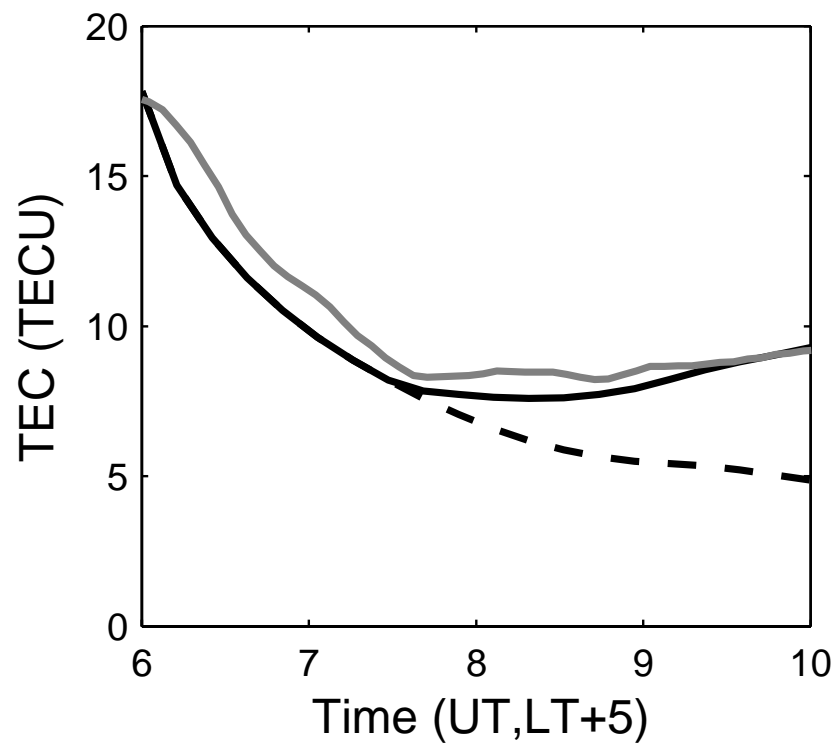

Fig. 12. Total electron content (TEC) from 200 to $450 \mathrm{~km}$ for the simulation results presented in Fig. 10 (dashed black) without flux, the simulation results presented in Fig. 11 (solid black) with flux, and the data (gray).

total electron content from $200-450 \mathrm{~km}$ for the two simulations (with and without flux) and for the data are compared in Fig. 12. The results are in reasonable agreement with the estimations above. The source of this flux is likely a meridional density gradient.

\subsection{Interpretation and variation of uplifts}

We have shown that uplifts occur fairly regularly in the equatorial ionosphere. The uplifts are not caused by a reversal of the zonal electric field, as shown in the case study presented in the previous section and as can be seen by looking at other datasets. However, comparisons to Jicamarca drifts indicate they occur when the vertical drift is small or decreasing, which allows recombination to become significant.

The source of the variation in the zonal field is related to variations in the thermospheric wind driving the $F$-region dynamo. These variations are associated with the midnight temperature maximum, or midnight pressure bulge, and a convergence of winds at low latitudes (e.g., Herrero et al., 1993; Faivre et al., 2006; Fesen, 1996; Sastri et al., 1994). Observations (e.g., Burnside et al., 1981; Herrero et al., 1993) have shown that there is an abatement in the meridional neutral wind associated with the pressure bulge. The $F$-region dynamo controls the magnitude of the zonal electric field and thus the decreasing zonal electric field is associated with the abatement in the dynamo winds. Presumably, the seasonal variations of the winds also contributes to the seasonal variations of the uplifts described in Sect. 2. 

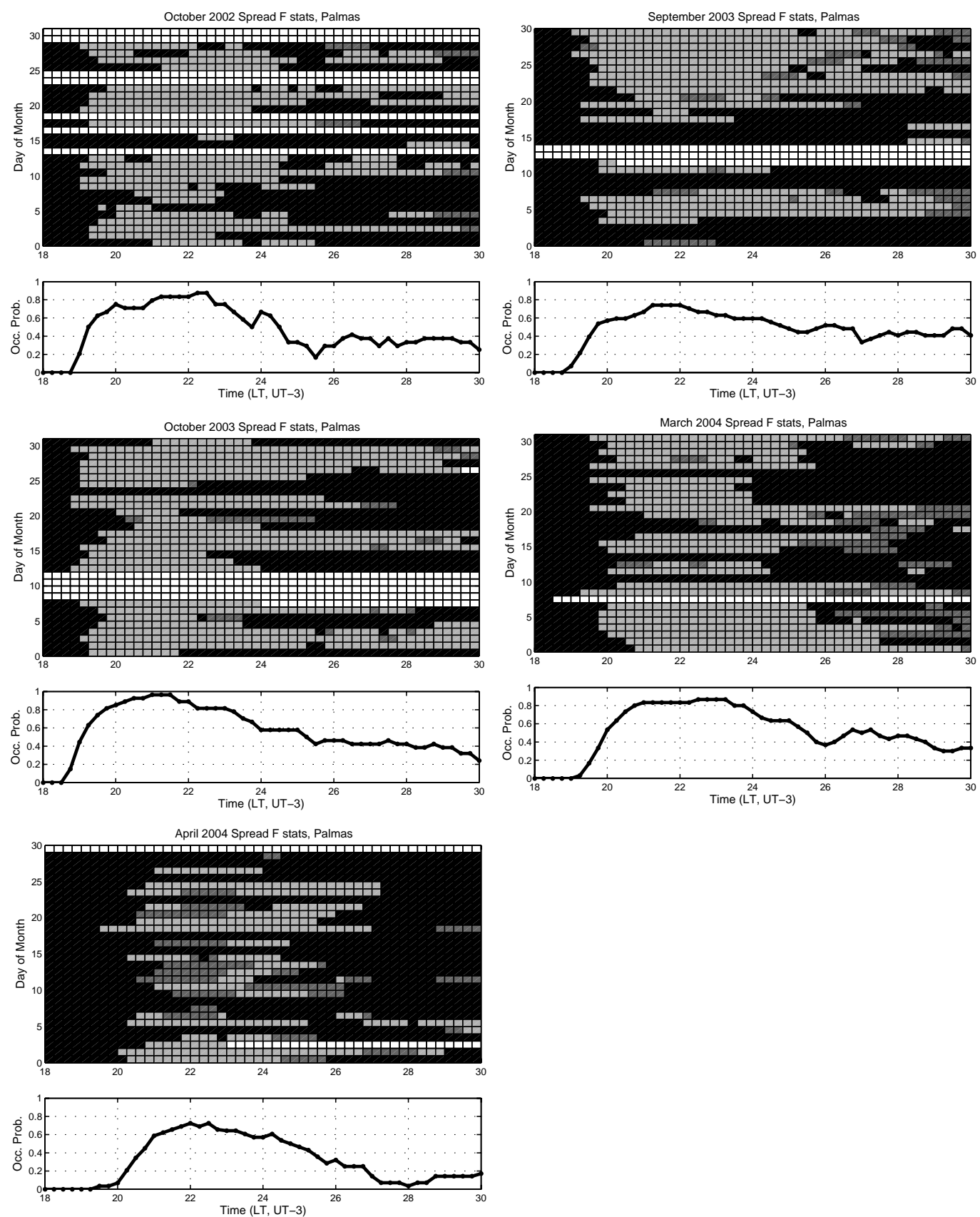

Fig. 13. Spread- $F$ statistics at Palmas for several equinox months in 2002, 2003, and 2004. The top panel is the spread- $F$ statistics for the entire month as a function of local time and night of month. White corresponds to no data, black corresponds to no spread- $F$, light gray corresponds to range spreading, and dark gray corresponds to frequency spreading. The lower panel is the averaged probability of occurrence of spread- $F$ for the month as a function of local time.

We have mentioned the fact that the magnitude of the uplifts is related to auroral electrojet activity. Storm-time effects can cause variations in the equatorial electric fields through changes in the global wind system, penetrating electric fields (e.g., Nishida et al., 1966; Vasyliunas, 1970; Kelley et al., 1979b), and disturbance dynamo winds driven by Joule heating (e.g., Blanc and Richmond, 1980). It is un- likely that the effects we are observing are due to penetrating electric fields since there are no rapid variations in the interplanetary electric field for the days we have examined. In addition, the under-shielding effect would cause a penetrating electric field that would be westward at these times, and we observe an eastward shift in the zonal field. However, weak disturbance dynamo effects could be causing the variations. 
A recent study by Richmond et al. (2003) has shown that at night the disturbance dynamo tends to drive a current that leads to reductions or reversals in the equatorial zonal electric field. This behavior appears to be consistent with the observations, an uplift and a decrease in the magnitude of the zonal electric field caused by weak auroral electrojet activity. From this explanation, it is clear how enhanced uplifts can occur during times of higher magnetic activity, when the dynamo disturbance becomes enhanced. As shown in the data from 1-2 October 2002 presented in Sect. 2, enhanced uplifts occur in response to geomagnetic activity. Storm-time effects induced for example by variations in the dynamo wind system could lead to an enhancement of pre-existing irregularities, leading to the behavior shown in Fig. 2.

It might be thought that the decrease in magnitude of the zonal electric field can be interpreted in terms of the reverse fountain effect (e.g., King, 1968). The so-called fountain effect is caused in the daytime by the zonal field which drives plasma upwards. The plasma can then fall down the field lines to low-latitudes where it creates the equatorial anomalies. At night, the reverse effect can occur. Downward drifts cause decreased plasma pressure on the topside, which can pull plasma from low-latitudes to the equatorial region. When this reverse fountain effect decreases in magnitude due to a decrease in the magnitude of the downward drift, an uplift can be caused via the mechanisms described already. The inclusion of recombination is essential to reproducing this uplift.

While the effect of the post-midnight wind abatement and the disturbance dynamo can explain the uplifts, it does not explain the density increase that is observed. The interpretation of the density increase in terms of the reverse fountain effect is not satisfactory because at the time of the uplift, the westward electric field is at its weakest and thus the plasma flux caused by the reverse fountain effect is also at its lowest. In order to explain this density increase, we have invoked a horizontal gradient in the meridional plasma flux in Sect. 4.1. This is an inward flux that could be driven by a westward electric field or by a convergence of neutral winds. But, as we have just stated, the observed westward electric field is becoming smaller, which should reduce the plasma flux, not increase it. Thus, the major source of the flux appears to be the convergence of the low-latitude winds associated with the midnight pressure bulge. Other studies have reported a density increase associated with the midnight temperature maximum or midnight pressure bulge (e.g., Arduini et al., 1997). At this time, it is unclear whether the pressure bulge is significant enough to drive the gradient in plasma flux that is required for this interpretation.

\subsection{Equatorial spread- $F$}

One of the potential implications of the post-midnight uplifts described in this paper is the generation of a secondary maximum in spread- $F$ occurrence rates. Many papers have described a secondary maximum in ESF occurrence in the post-midnight period (Abdu et al., 1981, 1983; Fejer et al., 1999; Hysell and Burcham, 2002; MacDougall et al., 1998). During periods of high geomagnetic activity, electric fields can penetrate to low latitudes and cause the equatorial electric field to reverse in the post-midnight period, which is a source of ESF during periods of high geomagnetic activity (Kelley et al., 1979b; Fejer et al., 1999). Hysell and Burcham (2002) divides the pre-sunrise ESF into two categories. The first, as described by Farley et al. (1970) and MacDougall et al. (1998), occur just before sunrise near the $F$ peak. The other may be due to "dead bubbles". Thus it seems possible that the uplifts described in this paper could contribute to the secondary maximum in ESF occurrence that occurs in the pre-sunrise period.

To illustrate that there is indeed a secondary peak in the ESF occurrence rate, we show Palmas ESF statistics in Fig. 13 for several equinox months. The top panel of each plot shows the statistics for each day of the given month, with range spreading distinguished from frequency spreading as described in the caption. The dominant occurrence peak can be seen between 20:00 and 22:00 LT with a decline in rate after that point. A secondary peak is seen in all but one of the curves (April 2004), with an occurrence rate of near 40\%, most pronounced in October 2002 and March 2004. The peak occurs between 02:00 and 04:00 LT. This corresponds nicely to the time of the uplifts, as depicted in Fig. 4. It is interesting to note that the ESF observed in the late morning is largely of the frequency type. This was also observed by Abdu et al. (1983).

\subsection{Extracting velocities from density measurements}

Recently, Woodman et al. (2006) have compared vertical drifts deduced from digisonde measurements to Jicamarca observations of the vertical drifts. The authors find fair agreement at times when strong convection dominates, for example near the pre-reversal enhancement, but poor agreement at times when production and recombination dominate. The digisonde drifts are deduced from the line-of-sight Doppler velocity, and such measurements have been relatively successful at high latitudes (e.g., Scali et al., 1995). Woodman et al. (2006) show that the agreement is worst in the postmidnight period, and attribute this disagreement to the relative importance of recombination. There have been other studies on the role of recombination at the equator (e.g., Bittencourt and Abdu, 1981).

There exists a very simple method for estimating the drift from the continuity equation. Equation (12) can be solved for the vertical velocity with a horizontal plasma flux term included,

$$
v_{z}=-\frac{\beta n_{e}+\partial n_{e} / \partial t+\partial\left(n_{e} v_{x}\right) / \partial x}{\partial n_{e}(z, t) / \partial z}
$$


which is valid for the nighttime equatorial ionosphere. The plasma flux term can be due to either meridional or zonal gradients in density. Given bottomside density measurements, one can calculate the time and altitude gradients to estimate the vertical velocity. The plasma flux, of course, is more difficult to measure, although we have demonstrated in this paper a simple method for estimating it given density measurements.

It is expected that digisonde drifts on average represent the motion of a constant density contour. Whether the drift is computed from the range rates of the echoes themselves or from the Doppler shifts shouldn't matter for total reflection. We show an example in Fig. 14 for 16 April 2002. The top panel shows three constant density curves as a function of time from the model case study presented in Fig. 11. The solid line with solid points in the bottom panel corresponds to the expected Doppler velocity that a digisonde would see, which corresponds to the change in height of a constant density contour as a function of time. This was averaged for the three contours in the top panel. The dashed line is the true velocity used in the simulation. It is clear that the "Doppler" velocity is way off and unphysical - the velocity is not even the correct direction. The results are consistent with those presented by Woodman et al. (2006) which show a positive drift during this time period, peaking between 02:00-04:00 LT. The crosses are the velocity estimates using Eq. (14), including the plasma flux term, which fall exactly on top of the model curve. The small variation is due to errors in estimating the gradients. The circles are the calculations using Eq. (14) but neglecting the plasma flux term, since that is in general difficult to estimate. Some error is induced by neglecting the flux, however the estimate is still very good compared to the Doppler result. Thus, it seems possible to estimate the vertical drifts using bottomside density profiles at times when the horizontal plasma flux is not too large. A similar technique was applied by Bertoni (2004) using the SUPIM model.

Note that both the recombination and the time derivative terms are quite important in general and neither should be neglected, at least in the post-midnight time period. During times of high convection (e.g., near the pre-reversal enhancement) recombination is negligible and the equation reduces to the motion of a constant density contour, as discussed by Woodman et al. (2006). Using Eq. (14), the Doppler velocities can also be corrected for the effects of recombination and plasma flux in the form,

$v_{z}=-v_{D}-\frac{\beta n_{e}+\partial\left(n_{e} v_{x}\right) / \partial x}{\partial n_{e}(z, t) / \partial z}$

where $v_{D}$ is the measured Doppler velocity.

\section{Conclusions}

We have shown observational evidence for post-midnight uplifts near the magnetic equator using data from a digital

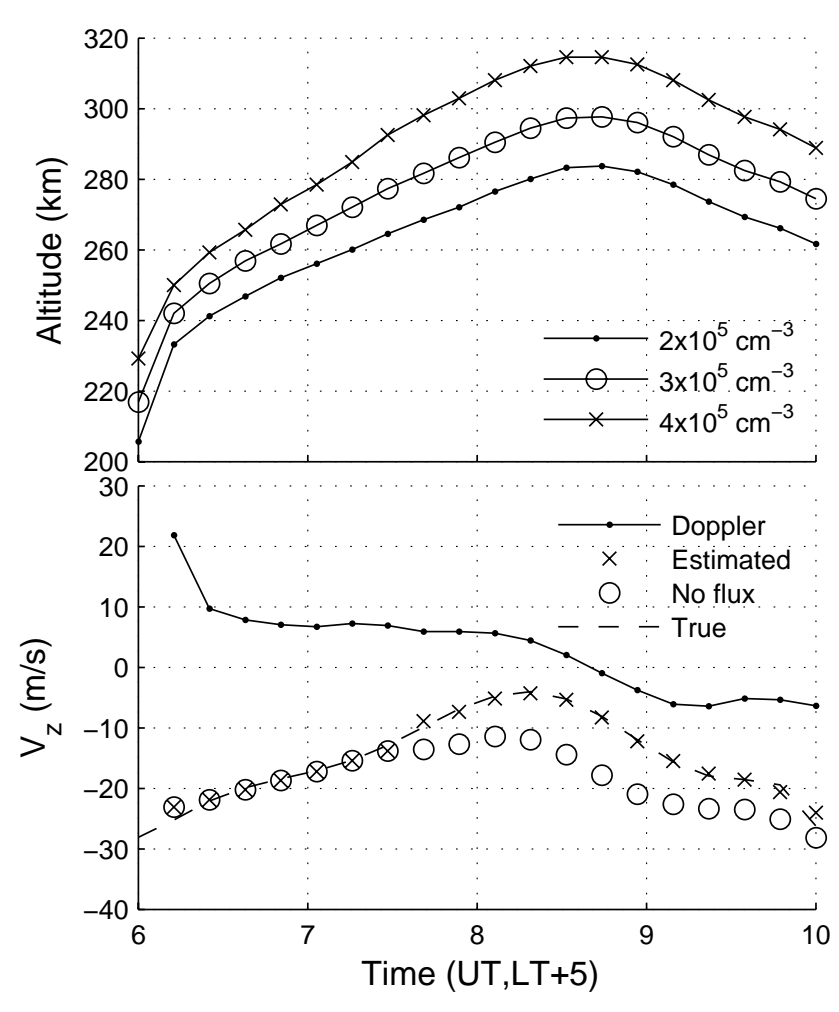

Fig. 14. The top plot shows three constant density contours using the model results presented in Fig. 11. The bottom plot shows the expected digisonde Doppler velocity (solid line with solid points), estimated velocity from density profiles (crosses), estimated velocity ignoring plasma flux (circles), and true velocity (dashed line).

ionosonde in Palmas, Brazil and by a digisonde at the Jicamarca Radio Observatory. These uplifts are in general not caused by a reversal in the zonal electric field, but such a reversal would enhance them, which may occur during active periods. During the time of uplift, the magnitude of the westward electric field decreases (but does not reverse) and recombination causes an apparent lifting of the layer, an increase in $h m \mathrm{~F} 2$. The change in the westward electric field during these time periods seems to be associated with an abatement of the equatorward neutral wind, induced by the midnight pressure bulge. Enhanced uplifts may be driven by auroral electrojet activity causing the disturbance dynamo to reduce the magnitude of the electric field, as studied by Richmond et al. (2003).

An interpretation of the uplift in terms of the reverse fountain effect cannot explain a density increase that is observed during the time of the uplift. In order to explain this increase, we have shown that horizontal plasma flux must be included in our model. These fluxes may be driven by meridional density gradients and a convergence of neutral winds at the equator associated with the midnight density maximum.

Density and height data can be used to estimate the plasma flux in the post-midnight sector. Jicamarca-measured drifts 
in combination with digisonde density measurements could be used to study this flux. Our simple model can be combined with density curves, for example measured by a digisonde, to estimate vertical drifts at the magnetic equator in the postmidnight period.

In addition, we have shown that the uplifts may contribute to a secondary maximum in the equatorial spread- $F$ occurrence rate that occurs in the post-midnight period. The extent of this maximum appears to agree quite well with the local-time variation of the uplifts.

Acknowledgements. The Jicamarca Radio Observatory is a facility of the Instituto Geofsico del Peru and is operated with support from the NSF Cooperative Agreement ATM-0432565 through Cornell University. Work at Cornell was sponsored by the Atmospheric Science Section of the NSF under Grant ATM-0000196. We thank two anonymous reviewers for their careful reading and detailed comments which have improved the paper.

Topical Editor M. Pinnock thanks M. Abdu and another referee for their help in evaluating this paper.

\section{References}

Abdu, M. A., Batista, I. S., and Bittencourt, J. A.: Some characteristics of spread $F$ at the magnetic equatorial station Fortaleza, J. Geophys. Res., 86, 6836-6842, 1981.

Abdu, M. A., de Medeiros, R. T., and Nakamura, Y.: Latitudinal and magnetic flux tube extension of the equatorial spread $\mathrm{F}$ irregularities, J. Geophys. Res., 88, 4861-4868, 1983.

Arduini, C., Laneve, G., and Herrero, F. A.: Local time and altitude variation of equatorial thermosphere midnight density maximum (MDM): San Marco drag balance measurements, Geophys. Res. Lett., 24, 377-380, 1997.

Banks, P. M. and Kockarts, G.: Aeronomy, Part B, Academic Press, Inc., New York, NY, 1973.

Bertoni, F.: Derivas ionsfericas em latitudes equatoriais: Observacoes e modelagem, Ph.D. thesis, Instituto Nacional de Pesquisas Espaciais, 2004.

Biondi, M. A., Sazykin, S. Y., Fejer, B. G., Meriwether, J. W., and Fesen, C. G.: Equatorial and low latitude thermospheric winds: Measured quiet time variations with season and solar flux from 1980 to 1990, J. Geophys. Res., 104, 17 091-17 106, 1999.

Bittencourt, J. A. and Abdu, M. A.: A theoretical comparison between apparent and real vertical ionization drift velocities in the equatorial $F$ region, J. Geophys. Res., 86, 2451-2454, 1981.

Blanc, M. and Richmond, A. D.: The ionospheric disturbance dynamo, J. Geophys. Res., 85, 1669-1686, 1980.

Burnside, R. G., Herrero, F. A., Meriwether, J. W., and Walker, J. C. G.: Optical observations of thermospheric dynamics at Arecibo, J. Geophys. Res., 86, 5532-5540, 1981.

Duncan, R. A.: The behaviour of a Chapman layer in the night $F_{2}$ region of the ionosphere, under the influence of gravity, diffusion, and attachment, Australian J. Phys., 9, 436-439, 1956.

Dungey, J. W.: The effect of ambipolar diffusion in the night-time $F$ layer, J. Atmos. Terr. Phys., 9, 90-102, 1956.

Faivre, M., Meriwether, J. W., Fesen, C. G., and Biondi, M. A.: Climatology of the midnight temperature maximum phenomenon at Arequipa, Peru, J. Geophys. Res., in press, 2006.
Farley, D. T., Balsley, B. B., Woodman, R. F., and McClure, J. P.: Equatorial spread $F$ : Implications of VHF radar observations, J. Geophys. Res., 75, 7199-7210, 1970.

Fejer, B. G., Farley, D. T., Woodman, R. F., and Calderon, C.: Dependence of equatorial $F$-region vertical drifts on season and solar cycle, J. Geophys. Res., 84, 5792-5796, 1979.

Fejer, B. G., Scherliess, L., and de Paula, E. R.: Effects of the vertical plasma drift velocity on the generation and evolution of equatorial spread F, J. Geophys. Res., 104, 19 859-19869x, 1999.

Feng, Z., Kudeki, E., Woodman, R. F., Chau, J., and Milla, M.: F region plasma density estimation at Jicamarca using the complex cross-correlation of orthogonal polarized backscatter fields, Radio Sci., 39, RS3015, doi:10.1029/2003RS002963, 2004.

Fesen, C. G.: Simulations of the low-latitude midnight temperature maximum, J. Geophys. Res., 101, 26 863-26 874, 1996.

Hedin, A. E.: Extension of the MSIS Thermospheric model into the middle and lower atmosphere, J. Geophys. Res, 96, 1159-1172, 1991.

Herrero, F. A., Spencer, N. W., and Mayr, H. G.: Thermosphere and $F$-region plasma dynamics in the equatorial region, Adv. Space Res., 13, 201-220, 1993.

Hysell, D. L. and Burcham, J. D.: JULIA radar studies of equatorial spread F, J. Geophys. Res., 103, 29 155-29 167, 1998.

Hysell, D. L. and Burcham, J. D.: Long term studies of equatorial spread $F$ using the JULIA radar at Jicamarca, J. Atmos. SolarTerr. Phys., 64, 1531-1543, 2002.

Kelley, M. C.: The Earth's ionosphere: Plasma physics and electrodynamics, Academic Press, Inc., San Diego, CA, 1989.

Kelley, M. C., Baker, K. D., and Ulwick, J. C.: Late time barium cloud striations and their possible relationship to equatorial spread F, J. Geophys. Res., 84, 1898-1904, 1979a.

Kelley, M. C., Fejer, B. G., and Gonzales, C. A.: An explanation for anomalous equatorial ionospheric electric fields associated with a northward turning of the interplanetary magnetic field, Geophys. Res. Lett., 6, 301-304, 1979 b.

Kil, H. and Heelis, R. A.: Global distribution of density irregularities in the equatorial ionosphere, J. Geophys. Res., 103, 407-417, 1998.

King, J. W.: Airglow observations and the decay of the ionospheric equatorial anomaly, J. Atmos. Terr. Phys., 30, 391-397, 1968.

Kudeki, E., Bhattacharyya, S., and Woodman, R. F.: A new approach in incoherent scatter $F$ region $\mathrm{E} \times \mathrm{B}$ drift measurements at Jicamarca, J. Geophys. Res., 104, 28 145-28 162, 1999.

MacDougall, J. W., Abdu, M. A., Jayachandran, P. T., Cecile, J. F., and Batista, I. S.: Presunrise spread $F$ at Forteleza, J. Geophys. Res., 103, 23 415-23 425, 1998.

Martyn, D. F.: Processes controlling ionization distribution in the $F_{2}$ region of the ionosphere, Australian J. Phys., 9, 161-165, 1956.

Nicolls, M. J. and Kelley, M. C.: Strong evidence for gravity wave seeding of an ionospheric plasma instability, Geophys. Res. Lett., 32, L05108, doi:10.1029/2004GL020737, 2005.

Nicolls, M. J., Kelley, M. C., Coster, A. J., González, S. A., and Makela, J. J.: Imaging the structure of a large-scale TID using ISR and TEC data, Geophys. Res. Lett., 31, L09812, doi:10.1029/2004GL019797, 2004.

Nishida, A., Iwasaki, N., and Nagata, T.: The origin of fluctuations in the equatorial electrojet: A new type of geomagnetic variation, Ann Geophys., 22, 478-484, 1966. 
Richmond, A. D., Peymirat, C., and Roble, R. G.: Long-lasting disturbances in the equatorial ionospheric electric field simulated with a coupled magnetosphere-ionosphere-thermosphere model, J. Geophys. Res., 108, 1118, doi:10.1029/2002JA009758, 2003.

Rishbeth, H. and Garriott, O. K.: Introduction to ionospheric physics, Academic Press, Inc., New York, NY, 1969.

Sastri, J. H., Rao, H. N., Somayajulu, V. V., and Chandra, H.: Thermospheric meridional neutral winds associated with equatorial midnight temperature maximum (MTM), Geophys. Res. Lett., 21, 825-828, 1994.

Scali, J. L., Reinisch, B. W., Heinselman, C. J., and Bullet, T.: Coordinated digisonde and incoherent scatter radar $F$ region drift measurements at Sondre Stromfjord, Radio Sci., 30, 1481-1498, 1995.

St.-Maurice, J. P. and Torr, D. G.: Nonthermal rate coefficients in the ionosphere: The reactions of $\mathrm{O}+$ with $\mathrm{N}_{2}, \mathrm{O}_{2}$, and $\mathrm{NO}, \mathrm{J}$. Geophys. Res., 83, 969-977, 1978.
Valladares, C. E., Basu, S., Groves, K., Hagan, M. P., Hysell, D., Mazzella, A. J., and Sheehan, R. E.: Measurement of the latitudinal distributions of total electron content during equatorial spread $F$ events, J. Geophys. Res., 106, 29 133-29 152, 2001.

Vasyliunas, V. M.: Mathematical models of magnetospheric convection and its coupling to the ionosphere, in Particles and Fields in the Magnetosphere, edited by: McCormac, M., D. Reidel, Norwell, MA, p. 60, 1970.

Vlasov, M. N., Nicolls, M. J., Kelley, M. C., Smith, S. M., Aponte, N., and González, S. A.: Modeling of airglow and ionospheric parameters at Arecibo during quiet and disturbed periods in October 2002, J. Geophys. Res., 110, A07303, doi:10.1029/2005JA011074, 2005.

Woodman, R. F., Chau, J. L., and llma, R. R.: Comparison of ionosonde and incoherent scatter drift measurements at the magnetic equator, Geophys. Res. Lett., 33, L01103, doi:10.1029/2005GL023692, 2006. 